\title{
COLLEMBOLAN FAUNA OF RAJSHAHI UNIVERSITY CAMPUS
}

\author{
Mosharrof Hossain* \\ Department of Zoology, University of Rajshahi, Rajshahi 6205, Bangladesh \\ *Email:mshzool@yahoo.com
}

\begin{abstract}
Collembola are small soil dwelling apterygot (wingless) arthropod which are found all over the world and in a great variety of habitats, from seashore to the highest peaks of the mountains. There are over six thousands described collembolan species in about 500 genera worldwide. In this study 72 and 52 individuals belonging to the genera Rambutsinella and Entomobrya (Collembola: Entomobryidae), respectively were identified. Perhaps this constitutes the first report on collembolan in Bangladesh.
\end{abstract}

Key words: Collembola, taxonomy, Entomobryidae, Rambutsinella, Entomobrya

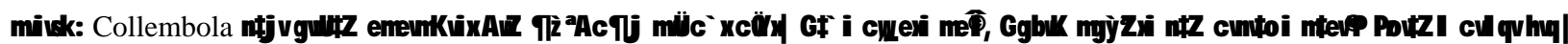

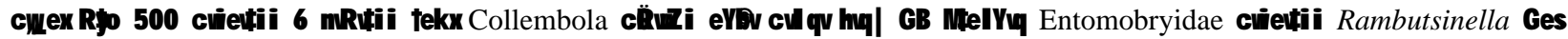

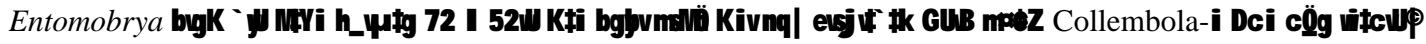

\section{Introduction}

Collembolans, commonly known as springtails, are the most abundant insects in the world. The name springtail comes from the springing organ or furcula that arose during evolution from a pair of appendages and fused at their bases. The word Collembola was first used by Sir John Lubbock (1873) to describe a peculiar characteristic, a special tube on the ventral side of the first abdominal segment which is a thin walled structure that has evolved for fluid exchange. These soft bodied tiny arthropods are amongst the smallest but most successful arthropods. They are found all over the world and in a great variety of habitats, from seashore to the highest peaks of the Himalayas. There are over 6000 described species in about 500 genera worldwide (Greenslade, 1991).

Collembola are found predominantly in the soil, leaf litter and other habitats such as logs and dung. Certain species are found on grasses, in flowers and under the bark of trees. An average square metre of soil in a temperate grassland or woodland yields at least 40,000 individuals Hopkin (1997). Many species inhabit in caves, interstitially in wet sand and under rocks including coral reefs and on water surfaces (Nayar et al. 1976). Although less important economically, these are quite significant ecologically. Because of their feeding habit they help in decomposition of fungal hyphae and general detritus in soil. Christiansen (1958), Gisin (1960), Stach (1963) and Mitra (1993) used easily visible morphological characters for describing Entomobryidae up to genera. Recently Zhang et al. (2009a, b) described new collembolans from India and eastern Asia. A review of literature reveals that there is no mentionable survey of Collembola in Bangladesh. This led to investigate the collembolan species in the Rajshahi University Campus.

\section{Materials and Methods}

Collection of test insects: Adult collembolans were collected mainly from grassland habitats located in the Rajshahi University Campus and its adjoining areas, from March to October 2005, at regular intervals. Usually each habitat was sampled once a week, but in case of failure, sampling was made on the next day.

Collection procedures: Grasses and leaf litters were selected carefully to collect the sample insects. Owing to their jumping nature, the insects were trapped easily in a white plastic plate covered with light glycerin, caught with the aid of an aspirator, transferred to small vials with the help of a camel hair brush, and finally preserved in $70 \%$ alcohol for further study.

Preparation of slides: The insects were dehydrated stepwise using 70\%, 90\%, 95\% and absolute (99.9\%) alcohol in individual vials. For each treatment the samples in the desired concentration of alcohol were kept in hot water for 5-10 min, and finally the samples were carefully transferred into carbylphenol from the last step of absolute alcohol. The dehydrated samples thus obtained could be preserved for a long period. The slides were prepared with aqueous gum-chloral mounting media for microscopic observations. Specimens were mounted in slides with Hoyer medium after cleaning with Nesbitt solution. The slides were examined under Olympus BX51-TF microscope with a multi-viewing system and an Olympus BX50-F4 was used for differential interference contrast (DIC). 


\section{Results and Discussion}

General morphology of Collembola: A brief morphological feature of Collembola is described here for convenience and ready reference, a detailed account of which is given by Hopkin (1997). These are small hexapods, most being only a few mm long. Adults are usually 1-3mm long but a few can reach up to10mm. Many species are white, black or with various shades of grey but others are multicoloured and patterned. These are furnished with setae which can be numerous or sparse, fine or thick, long or short, serrated, ciliated clavate or smooth. Scales and bothriotricha are found in some families. Setae play an important role in chaetotaxy.

The body can be divided into head, thorax and abdomen. The head bears a pair of antennae, a pair of eyes with a maximum of eight individual ocelli in each (some species are blind) and the mouthparts are entognathic i.e. held inside the head capsule. The antennae are composed of 4 segments, varying in length from shorter than head to longer than body, and sometimes modified in male as clasping organs. The thorax consists of three segments, each bearing a pair of legs, and are clearly distinguishable or fused to abdomen. Each leg is divided into 2 superficial subcoxae, coxa, trochanter, femur and tibiotarsus. The abdomen is six-segmented, but some abdominal segments may fuse together making the intersegment boundaries difficult to resolve. The first segment ventrally carries the ventral tube, and the third segment carries the retinaculum. The fourth segment bears the furca or spring organ, which is usually folded under the body and held in place by a catch, tentaculum on the third abdominal segment. The furcula consists of a fused area called the manubrium and a pair of structures called dentes. On the end of each dens, there is a hook like structure called mucro.

Identification: Standard keys (Greenslade 1991) were used to identify the Collembola up to the Family and genera. The characters considered for identifying the adults are shown in the table below.

\begin{tabular}{|ll|}
\hline $\begin{array}{l}\text { Terminologies } \\
\text { Antenna }\end{array}$ & $\begin{array}{l}\text { Explanation } \\
\text { (pl. antennae) Head bears a pair of 4-semented antennae, which can be sub-divided into numerous } \\
\text { Vertex }\end{array}$ \\
sub-segments, varying in length from shorter than head to longer than body. \\
Top point of the cephalic region. \\
(pl. furca) Springing organ consisting of a fused area called manubrium and a pair of structures \\
called dentes. \\
Curved or straight structure attached to furcula and bears a pair or more dentes. \\
Mucro & $\begin{array}{l}\text { A hook-like structure located at the end of each dens, may be bidentate or falcate. } \\
\text { Ocellus }\end{array}$ \\
Abdominal segment ocelli) A maximum number of 8+8 ocelli on a pigmented patch on each side of the head. \\
Scale & $\begin{array}{l}\text { Abdomen is 6-segmented each may be equal or subequal in length and may be separated or fused. } \\
\text { Body may be covered with various types of scale or without scale. Scales when present may be } \\
\text { Seta }\end{array}$ \\
& $\begin{array}{l}\text { dark pointed or blunt. } \\
\text { (pl. setae) The whole body or different parts of the body may be covered with different types of } \\
\text { setae (sparse, thick, long or short, serrated, clavate or smooth) in different numbers or may be } \\
\text { absent altogether. }\end{array}$ \\
\hline
\end{tabular}

The following genera of Collembola (Family Entomobryidae) were identified.

Genus: Rambutsinella (Deharveng and Bedos 1996)

Small size, about $0.75 \mathrm{~mm}$, whitish in color (Fig. 1A), eyes 2 to 4 on each side, pigmentation present on the body, sometimes extremely light (Fig.1). Scales hyaline and rounded without striation. No scale in the antennae, legs and ventral tube. Few dorsal macrochaetae present. Third antennal segment is shorter than second and forth segment wide with smooth setae (Fig.1B). Marco curved with a simple basal spine and claw (Fig.1C). No basal tubercle on dens present.

Genus: Entomobrya (Rondani 1861)

Body length up to $2.3 \mathrm{~mm}$ without antennae, basic colour golden yellow with black spots (Fig. 2A). Antennae are as long as half of the body (Fig. 2B) and are darker with the apical area of the first three segments. Usually small patch of diffuse pigment appears in the middle of the head. The eye patches 


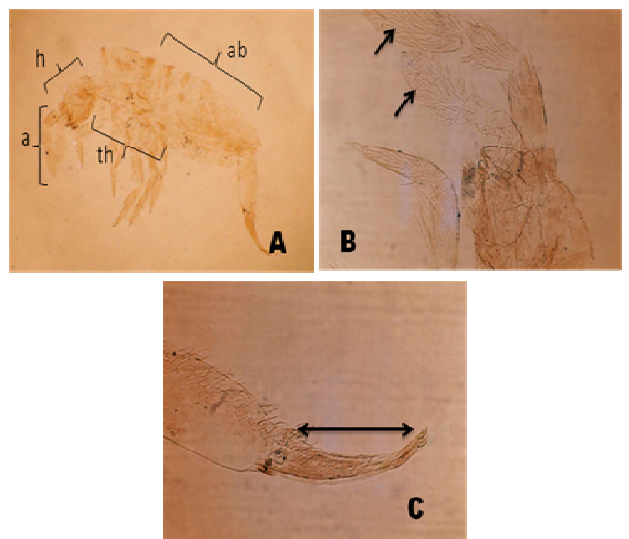

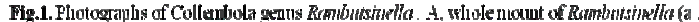

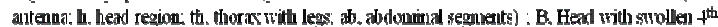

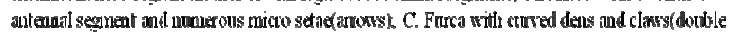
arrevi) (All plotograghs are $40 \mathrm{X}$ ).

always extend their pigment at the end of the lateral part of the head (Fig. 2C). Among the studied material some variation in colour has been noted, but the head chaetotaxy (Fig. 2C) is constant. Mucro bears anteapical teeth and mucronal spines (Fig. 2D). In contrast, however, the Nearctic species of Entomobrya bears an apical vesicle on the fourth antennal segment, and relative size of the head, length of the external setae of the labial appendage, setae morphology of the male genital plate, shape of the labral papillae, antennal length and longitudinal or transverse colour stripes (Christiansen 1958) are different from the present genus. But in agreement with Baquero and Jordana (2008), the present Entomobrya has setae in both labral and metatrochanteral organs.

The genera described above are usually found to share common habitats with grasshoppers and ants. This preliminary report on Collembola appears to be the first one in Bangladesh. However, a more extensive survey is solicited to explore the actual strength of the collembolan species diversity in the country.

\section{References}

Baquero E and Jordana R. 2008. Redescription of Entomobrya quinquelineata Börner, 1901 (Collembola: Entomobryidae) and description of three new species. Zootaxa 1821: 1-12.

Borror DJ and White RE. 1970. A Field Guide to Insects. Houghton Mifflin Co. Boston, New York. 404 pp.

Christiansen K. 1958. The Nearctic members of the genus Entomobrya (Collembola). Bull. Museum Comp. Zool. 118(7): 545.

Deharveng L and Bedos A. 1996. Rambutsinella, a new genus of Entomobryidae (Insecta: Collembola) from Southeast Asia. Raffles Bull. Zool. 44(1): 279-285.

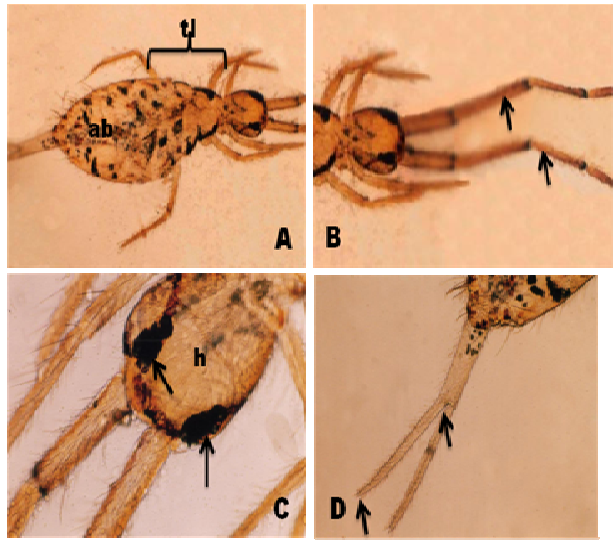

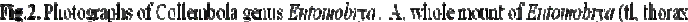

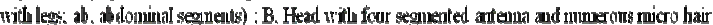

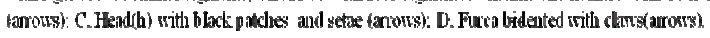
(All plotingaghts are $00 \mathrm{x}$ )

Gisin H. 1960. Collembolen fauna Europas. Museum de Histoire Naturelle, Genève, Switzerland. 312 pp.

Greenslade PJ. 1991. Collembola (Springtails). In: Insects of Australia: A Textbook for Students and Research Workers (ID Neumann ed.), pp. 252-264, Melbourne University Press, Australia.

Hopkin SP. 1997. Biology of the Springtails (Insecta: Collembola). Oxford University Press, UK. 330 pp.

Imms AD. 1964. A General Textbook of Entomology. Methuen \& Co., New York. 186 pp.

Lubbock J. 1873. Monograph of the Collembola and Thysanura. Royal Society of London. $276 \mathrm{pp}$.

Mitra SK. 1993. Chaetotaxy, Phylogeny and Biogeography of Paronellinae (Collembola: Entomobryidae). Calcutta Laser Graphics Pvt. Ltd. India. 100 pp.

Nayar KK, Ananthakrishnan TN and David BV. 1976. General and Applied Entomology. Tata McGraw-Hill Publ. Co. Ltd. New Delhi. 589 pp.

Oldroyed H. 1970. Collecting, Preserving and Studying Insects. Tetchinsum \& Co. Ltd. London. 336 pp.

Ross HH. 1966. A Textbook of Entomology. John Wiley \& Sons London. 226 pp.

Stach J. 1963. The Apterygotan fauna of Poland in relation to the world-fauna of this group of insects. Tribe: Entomobryini. Polska Akademia Nauk, Kraków, Poland. $126 \mathrm{pp}$.

Zhang F, Chatterjee T and Chen JX. 2009a. A new species of the genus Lepidocyrtus Bourlet and a new record of Seira delamarei Jacquemart (Collembola: Entomobryidae) from the east coast of India. Zootaxa 2310: $43-50$.

Zhang F, Deharveng L, Greenslade P and Chen JX. 2009b. Revision of Acanthocyrtus (Collembola: Entomobryidae), with description of a new genus from eastern Asia. Zool. J. Linnaean Soc. 157: 495-514.

Manuscript received on 12 August 2010 and revised on 25 November 2010. 